\title{
Is Wage Rate Dispersion a Good Index of Labor Market Integration? A Comment on Rothenberg
}

\author{
JOSHUA L. ROSENBLOOM
}

In a recent article in this JouRnAL, Winifred Rothenberg seeks to document the emergence of rural labor markets in late eighteenth and early nineteenth-century New England. ${ }^{1}$ Examining a rich body of wage data which she has collected from the account books of farmers, Rothenberg traces first temporal variations in the dispersion of wages, and then the pattern of variation in nominal and real wage rates over more than one hundred years. These aggregative measures of the operation of the labor market do not begin to exhaust the potential of the data which Rothenberg has accumulated, however, and I look forward to further and more detailed examinations of the behavior of farm wages in antebellum New England. Since such research is likely to be directed by the interpretation placed on the broad trends documented in her article, I offer the following comments to suggest fruitful lines of research.

According to Rothenberg, the existence of a "market process" can be confirmed by a trend decline in the dispersion of wage rates-as measured by the coefficient of variation. Rather than finding a monotonic trend convergence in this measure, however, she finds that the dispersion of general farm labor wage rates increased in the first half of the period, reaching a peak sometime shortly after 1800 , and then declined. While the onset of decline after this peak might indicate "the emergence of a market for farm labor by 1800 . . ." as Rothenberg proposes, other interpretations of the inverted $U$ shape pattern of wage dispersion are possible. ${ }^{2}$

In her article, Rothenberg identifies and dismisses two alternative explanations for the inverted- $\cup$ shape of dispersion over time: (1) that it is a statistical artifact produced by the greater number of wage observations in the middle years of the sample, and (2) that it is the result of a temporary increase in wage dispersion caused by the macroeconomic disturbances of the Revolutionary War. These alternatives do not exhaust the possibilities, however. Let me suggest two other explanations that need to be considered before we can firmly establish the hypothesis that the decline in wage dispersion after 1800 was a reflection of what Rothenberg terms the "market process."

The Journal of Economic History, Vol. XLIX, No. 1 (Mar. 1989). (C) The Economic History Association. All rights reserved. ISSN 0022-0507.

The author is Assistant Professor of Economics, University of Kansas, Lawrence, KS 66045.

He would like to thank Tom Weiss and an anonymous referee for their suggestions and comments.

${ }^{1}$ Winifred B. Rothenberg, "The Emergence of Farm Labor Markets and the Transformation of the Rural Economy: Massachusetts, 1750-1855," this Journal, 48 (Sept. 1988), pp. 537-66.

${ }^{2}$ The need to examine these alternatives is underscored by the fact that the inverted- $U$ shape pattern of wage dispersion is found only for general farm labor wages, not for task-specific pay rates. Rothenberg argues that the task-specific rates should be dropped from consideration on the grounds that "a single farm task or group of tasks is not an occupation," and thus we should not expect to find markets for these individual tasks (p. 542). If, as this argument implies, task-specific skills were not particularly important, so that workers could freely move between general farm labor and the performance of specific tasks, then we would expect any differences in task-specific pay at one location to be quickly eliminated as a result of competition, with the result that spatial differentials in these tasks would behave in the same way as those for general farm laborers. Of course, if different tasks were performed at different times of year, then task-specific rates of pay would not necessarily be equalized, but across-task differences in the behavior of spatial differentials could then be attributed to differences in the dates at which wage observations were recorded. In either event, it appears desirable to pin down the reasons why the different wage series display different patterns of dispersion over time. 
First, in addition to controlling for changes in the number of wage observations, it appears important to control for changes in the geographic dispersion of these observations. Strictly speaking, we would expect increasing market arbitrage to reduce wage differentials only between a fixed set of locations. Addition of new, more distant locations or changes in the number of observations from different locations could easily counteract, or reverse any trend decline in dispersion among a fixed group of locations. As Rothenberg herself notes, the introduction of account books from "frontier towns" in which labor was especially scarce may be a source of increasing dispersion (p. 548). If the frontier towns were removed, would the time pattern of wage dispersion look significantly different? Direct inspection of the locations and dates of the wage observations sheds little light on the effects of changes in the composition of the sample. To resolve this question we need to compare the reported wage dispersion with that computed for a standardized set of locations.

Second, other macroeconomic disturbances besides the Revolution may have influenced wage dispersion. Examination of geographically specific wage data from the latter part of the nineteenth century suggests that fluctuations in the degree of geographic dispersion were closely linked to fluctuations in aggregate economic activity. ${ }^{3}$ To illustrate this point, the lower panel of Figure 1 plots the coefficient of variation of real wage rates computed for several different occupations in 12 major U.S. cities from 1870 to 1898 . Two peaks are evident in this figure: the first, around 1875 , coincides with the post-Civil War deflation and the economy's recovery from the severe depression which began in 1873; the second, sometime after 1890, corresponds to the depression of the 1890 s. In contrast, the more stable economic growth of the 1880 s produced relatively low wage dispersion. ${ }^{4}$

The explanation for the fluctuation of wage dispersion seems to lie in the movements of wage levels, which are traced in the upper panel of Figure 1. The large fluctuations in economic activity and the cost of living which took place in the 1870 s and 1890 s were reflected in correspondingly large movements in wage levels, while the relatively tranquil 1880s saw much smaller movements in wages. Visual inspection of the underlying wage series suggests that the movements of wages in the different cities were roughly correlated, but that differences of one or two years in the timing with which they responded to macroeconomic fluctuations opened up large, but transitory differentials. The average wage series plotted in Figure 1 blur together abrupt wage movement in individual cities. Thus, wage dispersion rose toward a peak as wages began to change, but as the changing macroeconomic conditions were reflected in more and more of the cities, wage levels converged and dispersion declined.

On the basis of the results published by Rothenberg it is not possible to determine whether the peak in wage dispersion around 1800 reflects a similar pattern of relatively close correlation in wage movements accompanied by small differences in timing, but, judging from the behavior of average wages, it seems that wage movements were more

${ }^{3}$ Fluctuations in geographic dispersion are not unique to the labor market. The large literature on late nineteenth-century capital markets has stressed the integration which occurred over time, and not the variation in dispersion that manifested itself on occasion. The coefficient of variation of regional interest rate data for the period 1870 to 1914 shows peaks and troughs, however, that correspond closely to those illustrated in Figure 1. This suggests that some caution should be exercised in distinguishing between the trend reduction and cyclical variations in interest rate dispersion. See Gene Smiley, "Interest Rate Movements in the United States, 1888-1913," this JoURNAL, 35 (Sept. 1975), pp. 591-620.

${ }_{4}$ The decline in dispersion between the two peaks appears to be attributable to the convergence of wages in San Francisco toward those in the other cities in the sample, and is not a symptom of any more general wage convergence. See Joshua L. Rosenbloom, "Labor Market Institutions and the Geographic Integration of Labor Markets in the Late Nineteenth-Century United States' (Ph.D. diss., Stanford University, 1988), chap. 3. 

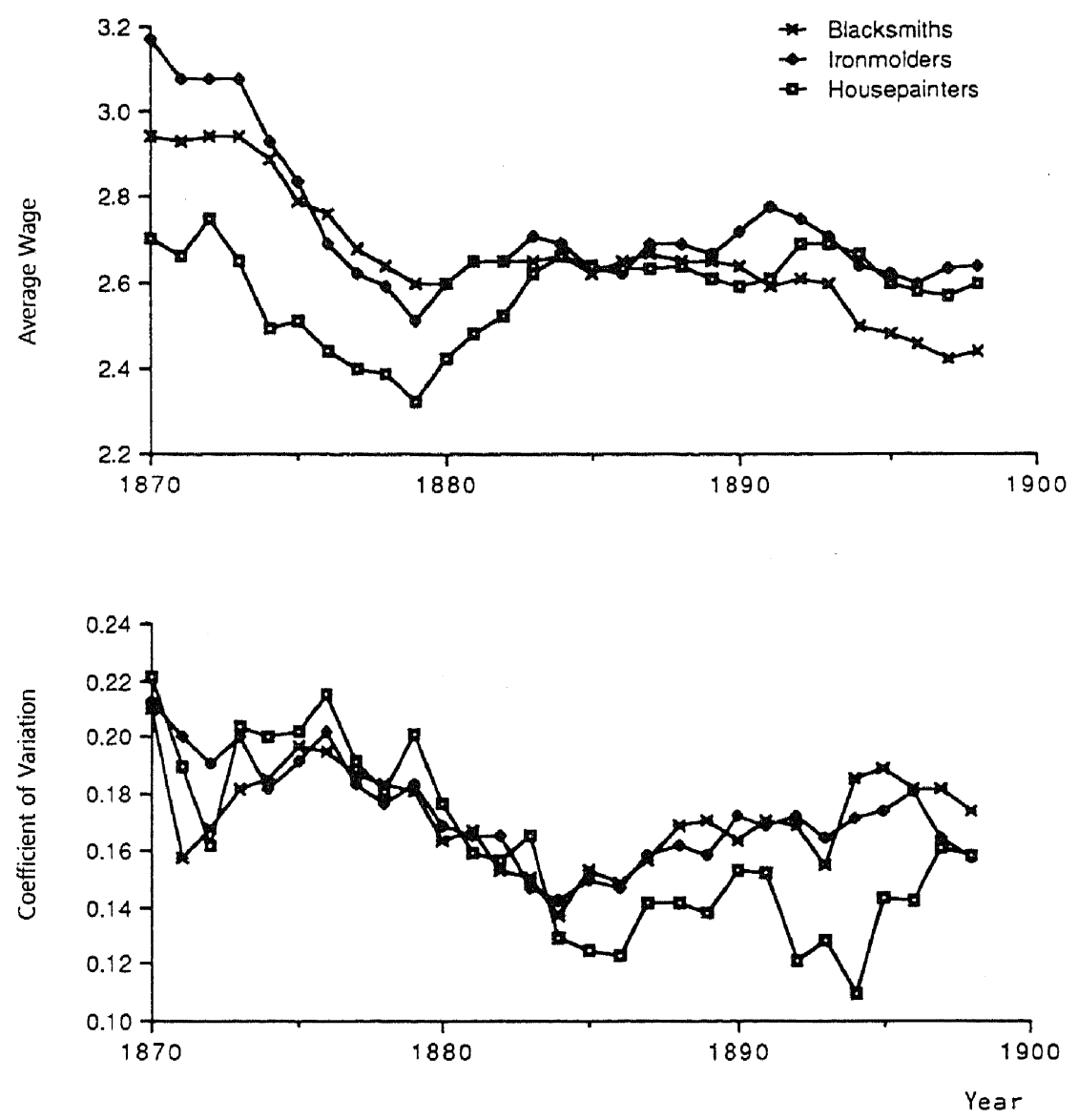

FIGURE 1

\section{AVERAGE WAGE LEVEL AND COEFFICIENT OF VARIATION OF WAGES IN TWELVE U.S. CITIES}

Notes and Sources: This figure shows the average wage level and the coefficient of variation of nominal wages deflated by a city-specific index of relative living costs. The cities included in the calculations are: Baltimore, Boston, Chicago, Cincinnati, New Orleans, New York, Philadelphia, Pittsburgh (including Allegheny), Richmond, St. Louis, St. Paul, and San Francisco. Nominal wages are from U.S. Department of Labor, "Wages in the United States and Europe, 1870 to 1898," Bulletin of the Department of Labor, no. 18 (Sept. 1898), pp. 665-93. The construction of the city-specific cost of living indices is described in Joshua L. Rosenbloom, "Labor Market Institutions and the Geographic Integration of Labor Markets in the Late Nineteenth-Century United States" (Ph.D. diss., Stanford University, 1988), chap. 3.

volatile at the turn of the century than they were either earlier or later. ${ }^{5}$ Before drawing any firm conclusions, however, it would be helpful to look at the individual wage series to see how their movements are related to variations in the overall index of dispersion. Additional light might also be shed on this question by a study of wage dispersion within

${ }^{5}$ One might object that it is unreasonable to attribute a single peak in a one hundred year sample to the same forces which induced two peaks in a period of less than thirty years at the end of the nineteenth century. The single peakedness, however, may be just a product of Rothenberg's technique of regressing the coefficient of variation on a polynomial time trend in order to find a single turning point in the data. The low values of $R^{2}$ reported for these regressions suggest, however, that there is a good deal of temporal variation in the coefficient of variation which is not explained by the simple inverted- $U$ shape of the fitted equation. Thus, the peak around 1800 may simply reflect a somewhat larger than normal set of disturbances. To resolve this question it is necessary to look more closely at the underlying data. 
individual communities. Since many of the account books come from just a few placesDeerfield stands out in particular-it would be interesting to see how well the market operated within a single, geographically confined community. If wage dispersion in a single community parallels that for broader regions, then this would suggest that fluctuations in wage dispersion were a reflection of differences in the stickiness of wage adjustment in periods of rapid change in the economy.

The primary purpose of this comment has been to suggest several additional factors which might influence wage dispersion, and not to discuss the conceptual framework within which this measure may be used as the criterion for the existence of markets. It seems worthwhile to ask, however, what we should conclude if subsequent investigation reveals that in fact there was no time trend in wage dispersion from 1750 to 1855 ? For Rothenberg, arbitrage is the defining feature of the labor market, with the result that wage convergence becomes the test of the market. But the market may also be viewed more broadly as a mechanism through which all exchanges are facilitated, and as such its operation will reflect the interplay of the different objectives of the participants. ${ }^{6}$ While the search for economic advantage is likely to be the predominant reason for exchange it is not the only one-a point clearly illustrated by the example of Abner Sanger. Although Sanger knew of the existence of higher paying employment elsewhere, he chose not to pursue it, presumably because this pursuit inhibited his achievement of other objectives. ${ }^{7}$ If variables other than income enter workers' utility functions, and hence affect their decisions along with the search for the highest wage, should we conclude that a market does not exist? Perhaps the question should not be just that of the existence or nonexistence of a market, but of its nature. What mechanisms facilitated exchange? What ends did they serve? And how have the answers to these questions changed over time?

${ }^{6}$ Philip Mirowski, "What Do Markets Do? Efficiency Tests of the 18th-Century London Stock Market," Explorations in Economic History, 24 (Apr. 1987), pp. 107-29, makes this point in the context of the performance of the eighteenth century London stock market. According to Mirowski, the persistent and systematic deviation of share prices from the levels predicted by efficient market models can be understood as a result of the other roles which stock ownership played-especially in giving share holders a vote on their company's actions.

7 Winifred B. Rothenberg, "The Emergence of Farm Labor Markets," pp. 554-55. Even today, when markets seem to be well established, the widening of interregional differentials in per capita income during the last decade indicates that objectives besides the maximization of current income continue to play an important role in labor market decisions. See Lindley H. Clark, Jr. "Prosperity Increasingly Tied in Part to Map," Wall Street Journal, 6 October 1988, p. A2. 